\title{
Formação de professores, saberes docentes e práticas educativas: a qualidade da educação infantil como centralidade
}

\author{
Dirléia Fanfa Sarmento \& Paulo Fossatti \\ Centro Universitário La Salle de Canoas, Brasil \\ Fernando Ribeiro Gonçalves \\ Universidade do Algarve, Portugal
}

Resumo

O artigo focaliza os saberes docentes que permeiam as práticas educativas de professores que exercem a docência em escolas de Educação Infantil no Brasil, participantes do Programa de Formação Continuada "Escola em Movimento: Saberes e Fazeres em Cena". Enfatiza que o aumento nos indicadores de qualidade da educação pressupõe a existência e efetivação de políticas públicas direcionadas para o monitoramento de tais indicadores, a formação dos gestores e docentes e a oferta e manutenção de condições que viabilizem os processos de ensino e de aprendizagem.

\section{Palavras-chave}

Formação de professores; Saberes docentes; Práticas educativas; Indicadores de qualidade da educação

\section{Introdução}

A universalização e a qualidade da educação são preocupações mundiais e têm suscitado discussões em diversos segmentos. Exemplo disso são os programas, em nível internacional, desenvolvidos e coordenados pela Organisation for Economic Cooperation and Development (OECD) com 0 
objetivo de mapear os indicadores que indiquem a efetividade dos sistemas educacionais (Programme for International Student Assessment - PISA) e os ambientes de aprendizagem e condições de trabalho dos professores (International Research on Teaching and Learning - Talis). No Brasil, além desses programas, coordenados pelo Instituto Nacional de Estudos e Pesquisas Educacionais "Anísio Teixeira" (INEP), a qualidade da educação brasileira tem sido monitorada através do Sistema de Avaliação da Educação Básica (SAEB), o qual gera informações sobre a qualidade, a equidade e a eficiência da educação básica nacional. Os dados obtidos são traduzidos no Índice de Desenvolvimento da Educação Básica (IDEB) e viabilizam a proposição de políticas públicas, programas e projetos que possam contribuir para a melhoria da qualidade da educação no país (Bonamino, 2002).

O Brasil faz parte do grupo de nove países que, em conjunto, concentram $67 \%$ dos 759 milhões de analfabetos do planeta. Juntos, tais países somam aproximadamente 3,5 bilhões de habitantes (mais de $50 \%$ da população mundial), sendo que, destes, 343 milhões têm idade equivalente à da escolarização inicial (Relatório de Monitoramento dos Objetivos de Educação para Todos, 2010). No que tange a Educação Infantil, no Brasil ela é considerada um direito da criança e uma obrigação do Estado, assegurado pela Constituição Federal, sendo ela definida na Lei de Diretrizes e Bases da Educação Nacional (LDB de 1996) como a primeira etapa da Educação Básica. A criança não é obrigada a frequentar, mas o poder público tem o dever de atendê-la. Com a reestruturação do Ensino Fundamental para nove anos (Lei $n^{\circ} 11.274$, de 6 de fevereiro de 2006), a Educação Infantil passou a compreender o atendimento de crianças entre 0 e 5 anos de idade em duas etapas: em creches até 3 anos e em pré-escolas de 4 a 5 anos. Uma das metas do Plano Nacional de Educação para o decênio 2001-2010 era de atender, neste período, $50 \%$ das crianças situadas na faixa etária entre 0-3 anos e $80 \%$ das crianças na faixa entre 4-6 anos. Vieira (2010, p. 819), ao analisar tal meta e os dados efetivos da taxa de escolarização das crianças de 0 a 6 anos, conclui que:

(...) a taxa de escolarização das crianças na faixa de idade de 0 a 6 anos ainda é baixa, tendo atingido a cobertura de $45,8 \%$, em 2008 . No entanto, quando analisamos esse índice de forma desagregada, verificamos que é cada vez mais generalizado o acesso à pré-escola, para crianças a partir de 4 anos de idade. (...) A proporção de crianças, na faixa etária de 4 a 6 anos, que 
frequentava escola em 2008 alcançou a média nacional de $80 \%$, índice que responde com anterioridade à meta prevista para 2010. (...) desde o início desta década, conforme resultados das PNAD/IBGE, o atendimento de crianças de 4 a 6 anos com rendimento médio familiar acima de três salários mínimos está perto da universalização.

Ter uma educação de qualidade desde a Educação Infantil é um direito da criança, pois tal educação poderá se constituir num entrave ou num facilitador para seu desenvolvimento e aprendizagem no decorrer de sua trajetória escolar. Dessa forma, "(...) é preciso evitar uma educação pobre para crianças pobres e a redução da qualidade à medida que se democratiza o acesso" (Brasil, 2001). Vale destacar que os índices obtidos através da avaliação externa que são referenciais em termos de indicadores da qualidade da educação (por ex., a Provinha Brasil, aplicada aos alunos da $4^{a}$ série) são resultados de um processo educacional que teve início já na Educação Infantil. Portanto, para intervir nestes índices é preciso um acompanhamento longitudinal das práticas educativas ao longo do processo de escolarização, tendo como uma das possíveis referências a Educação Infantil.

Há uma relação intrínseca entre a qualidade da educação, a qualidade da formação dos professores e de suas práticas educativas. Implicadas nestas duas dimensões estão as questões da trajetória e dos saberes docentes mobilizados em tais práticas. Contudo, devido à complexidade do processo educativo não é possível reduzir a qualidade da educação somente aos aspectos já referidos, sendo necessário identificar e problematizar outras dimensões que interferem em tal processo que extrapolam a ação do professor. Em relação à formação de professores, o Plano Nacional de Educação, com base na Lei de Diretrizes e Bases da Educação Nacional, salienta que:

A formação dos profissionais da educação infantil merecerá uma atenção especial, dada a relevância de sua atuação como mediadores no processo de desenvolvimento e aprendizagem. A qualificação específica para atuar na faixa de 0 a 6 anos inclui o conhecimento das bases científicas do desenvolvimento da criança, da produção de aprendizagens e a habilidade de reflexão sobre a prática, de sorte que esta se torne, cada vez mais, fonte de novos conhecimentos e habilidades na educação das crianças. Além da formação acadêmica prévia, requer-se a formação permanente, inserida no trabalho pedagógico, nutrindo-se dele e renovando-o constantemente. 
Em termos analíticos, neste texto se faz a opção em focalizar o Programa de Formação Continuada "Escola em Movimento: Saberes e Fazeres em Cena", direcionando o olhar para os saberes docentes (Tardif, 2010) que permeiam as práticas educativas de professores que exercem a docência na Educação Infantil em escolas da rede municipal da cidade de Canoas, participantes deste Programa. De acordo com dados do Instituto Brasileiro de Geografia e Estatística (IBGE), Canoas possui 323.827 habitantes (Censo 2010), sendo a quarta cidade com maior população do Estado do Rio Grande do Sul (Brasil). Na rede municipal de ensino público, 42 escolas são de Ensino Fundamental e 31 de Educação Infantil. O número de escolas infantis não atende a demanda existente, sendo que várias crianças ainda não possuem acesso a Educação Infantil. A realidade sócio-econômica das famílias cujos filhos estudam em tais escolas é diversa, sendo que é possível constatar desde famílias em situação de vulnerabilidade social até famílias com um nível sócio-econômico privilegiado.

Um dos desafios assumidos pela atual gestão municipal, no âmbito da educação, é atingir as metas nacionais projetadas relativas ao IDEB. Dessa forma, com base na análise dos resultados do IDEB obtidos por cada uma das escolas de Ensino Fundamental da rede, foram delineadas políticas públicas visando o aprimoramento da qualidade de ensino no município. Dentre tais políticas, destacam-se os investimentos: na ampliação e revitalização das escolas de Educação Infantil e Ensino Fundamental; na valorização do magistério, a partir da reestruturação do plano de carreira; na formação de professores e gestores; e na pesquisa, estabelecendo uma parceria com a universidade. Nesse cenário se situa o Programa de Formação Continuada "Escola em Movimento: Saberes e Fazeres em Cena".

\section{Programa de Formação Continuada "Escola em Movimento: Saberes e Fazeres em Cena": contexto da proposta}

O Programa de Formação Continuada "Escola em Movimento: Saberes e Fazeres em Cena"1 é um programa de formação que faz parte de uma política pública municipal cujos participantes são os profissionais que atuam em escolas da rede municipal da cidade de Canoas. Em sua primeira edição, contempla 84 diretores e vice-diretores, 22 orientadores, 22 supervisores e 351 professores que atuam na Educação Infantil e Ensino 
Fundamental. Ao se contemplar no Programa todos estes atores, parte-se do princípio de que o aprimoramento dos processos e práticas educativas é um compromisso que deve ser assumido por toda a comunidade educativa. Objetiva "Propor espaços formativos que viabilizem a reflexão, a avaliação e a projeção de estratégias de caráter intervencionista para qualificar as práticas dos gestores e professores visando à melhoria dos indicadores de desempenho dos alunos da Rede Municipal de Canoas". Tem como eixos estruturantes, dentre outros, os seguintes conceitos e pressupostos: a epistemologia da prática, o professor reflexivo e a escola reflexiva (Alarcão, 1996, 2001; Schön, 1992, 2000); a auto-hetero observação e análise da relação educativa (Ribeiro Gonçalves, 1993, 2006, 2010a, 2010b); os saberes docentes (Tardif, 2010); a pesquisa-ação colaborativa (Franco, 2005; Kemmis \& McTaggart, 1992; Monceau, 2005; Pimenta, 2005; Lewin, 2006); e a inovação pedagógica (Carbonell, 2002; Correia, 1991).

O modelo formativo está fundamentado em quatro pilares que se interrelacionam dialogicamente: auto-hetero observação e análise da relação educativa; identificação de necessidades e projeção de estratégias de formação individual e coletiva; intervenção no contexto educativo; e investigação sobre a prática educativa. Um dos objetivos da observação e análise da relação educativa é possibilitar a emergência de uma prática cada vez mais sólida e adequada ao real através do ciclo de observar para diagnosticar, diagnosticar para avaliar, avaliar para decidir e decidir para atuar. A complexidade da relação educativa convida a refletir sobre e tentar compreender as diferentes variáveis que interferem em sua qualidade. Dessa forma, a observação (seja auto ou hetero-observação) e a partilha de seu conteúdo viabiliza a avaliação, que, por sua vez, se entendida num sentido formativo, possibilita a identificação de temáticas a serem incluídas no projeto formativo de cada um dos atores que atuam no contexto educativo e a projeção de estratégias de formação individual e coletiva.

Existe uma relação intrínseca entre investigação, inovação e formação, tal como aponta Ribeiro Gonçalves (2010b). Assim, para que o professor seja um profissional reflexivo, inovador e criativo em seu fazer pedagógico, é necessário que ele se constitua num investigador de si mesmo e dos contextos em que atua, comprendidos em suas dimensões micro e macro estruturais. Esse olhar reflexivo sobre si mesmo pode contribuir para a 
tomada de consciência das suas ações, viabilizando a identificação das razões organizativas que mobilizam determinados comportamentos no exercício da docência. Este argumento coincide com o que Hedges (2012) recentemente apontou como fundamentos dos conhecimentos que os professores utilizam nas suas tomadas de decisão e, consequentemente, na organização das suas práticas. Nesse texto são apontadas várias dimensões que contribuem para a construção dos saberes do professor e entre as quais destacamos: conhecimentos provenientes da vivência familiar; valores e crenças do professor; influências das experiências vividas durante a sua formação escolar; e conhecimentos construídos nos processos de formação inicial e continuada.

Todas as ações formativas são acompanhadas por investigações científicas $^{2}$ conduzidas por pesquisadores que exercem a docência no Mestrado em Educação do Centro Universitário La Salle, mestrandos e graduandos bolsistas de iniciação científica participantes do grupo de pesquisa, coordenado por uma das autoras deste texto, denominado "Práticas Educativas e Indicadores de Qualidade da Educação".

O escopo atual ${ }^{3}$ do Programa está estruturado em três ciclos formativos que, numa visão de espiral, têm como cerne a relação dialógica entre a prática educativa, a investigação e a formação. No ciclo formativo 1 , equivalente a 180 horas, os professores são instrumentalizados para se constituírem em investigadores de sua própria prática, revisitar seus saberes e redimensionar o seu fazer pedagógico. Entram em cena os encontros formativos, espaços estes de reflexão e articulação teórico-metodológica. Este processo se efetiva com o acompanhamento dos pesquisadores e demais profissionais que tematizam conteúdos formativos específicos, os quais possuem a função de assessorar o professor no processo de reflexão sobre o seu fazer pedagógico cotidiano. Os professores, dependendo do nível e ano que exercem a docência, são organizados em grupos de formação, de forma a se atender as características e especificidades relativas a cada ano. No ciclo formativo 2, com 375 horas, realizado no formato de curso de especialização, lato sensu, os professores elegem um dos eixos temáticos investigativos elencados problematizando-o de forma sistemática e científica e apresentando suas reflexões dentro de um projeto de pesquisa estruturado, o qual será transformado na monografia de conclusão de curso. No ciclo 
formativo 3, em nível de pós-graduação, stricto sensu, os professores aprovados no processo seletivo do Curso Mestrado em Educação oferecido pelo Unilasalle recebem bolsa integral financiada pela Prefeitura Municipal para realizar seus estudos.

\section{Metodologia}

O estudo investigativo realizado com as professoras da Educação Infantil situa-se no campo da pesquisa-ação colaborativa, tendo por base a definição de Franco (2005, pp. 485-485), a qual explica que

(...) quando a busca de transformação é solicitada pelo grupo de referência à equipe de pesquisadores, a pesquisa tem sido conceituada como pesquisaação colaborativa, em que a função do pesquisador será a de fazer parte e cientificizar um processo de mudança anteriormente desencadeado pelos sujeitos do grupo.

E, mais especificamente, na dimensão da pesquisa-ação enquanto postura que alimenta a noção de pesquisa como forma de compromisso político, de pensamento crítico sobre o poder e seus privilégios, de promover as relações colaborativas como pano de fundo para a constituição de comunidades de aprendizagem envolvidas na mudança e qualidade das práticas e dos sistemas educativos (Brydon-Miller \& Maguire, 2009). Esta perspectiva sustenta e constituiu-se como exigência para a organização dos encontros reflexivos e formativos descritos neste texto.

Dessa forma, a pesquisa ampara-se num conjunto de estudos já realizados tendo como foco a rede municipal de ensino de Canoas (Sarmento, Pauly, Nogueira, \& Fossatti, 2009; Rapoport, Sarmento, Nornberg, \& Pacheco, 2008; Sarmento \& Rapoport, 2009a, 2009b) e em pressupostos de autores tais como Fullan e Hargreaves (2000), Tardif (2010) e Pimenta (2005), que sinalizam para a importância da formação continuada e das concepções e saberes docentes. A opção pela pesquisa ação se justifica por seu caráter de implicação e transformação da realidade por parte dos pesquisadores envolvidos, pois: "Se alguém opta por trabalhar com pesquisa-ação, por certo tem a convicção de que a pesquisa e ação podem e devem caminhar juntas quando se pretende a transformação da prática" (Franco, 2005, p. 485). Para Kemmis e McTaggart (1992), realizar pesquisa-ação, implica planejamento, ação, observação, reflexão cuidadosa, sistemática e regular, para além da 
observação da vida cotidiana. Para eles, ao pesquisador envolvido com pesquisa-ação competem quatro tarefas básicas, a saber: o plano é ação organizada e antecipa a ação; a ação é deliberada e controlada; a observação tem função de documentar os efeitos da ação criticamente informada; e a reflexão rememora a ação tal como tem ficado registrada pela observação, sendo, contudo, também um elemento ativo.

Kemmis e McTaggart (1992) sugerem a efetivação de quatro etapas na pesquisa-ação: 1) diagnóstico-reconhecimento e fortalecimento de identidade de grupo; 2) planejamento das ações; 3) aplicação de estratégias de ação, processo de observação-registro; e 4) avaliação, reflexão e reorganização. Considerando que a pesquisa está em desenvolvimento, neste texto são apresentados os dados coletados relativos às duas primeiras etapas da investigação já realizadas, a saber:

a) $1^{a}$ Etapa: Diagnóstico-reconhecimento e fortalecimento de identidade de grupo. $O$ trabalho com o coletivo de participantes do estudo é um dos aspectos fundamentais na pesquisa-ação. Dessa forma, nesta etapa do estudo, foram realizados dois encontros formativos, com duração de 3 horas cada. $O$ objetivo do Encontro I foi a integração entre as professoras e o desenvolvimento do sentimento de pertença ao processo investigativo. A integração e o sentimento de pertença são pré-requisitos para o engajamento na pesquisa, incidindo sobre os resultados almejados. Os pesquisadores apresentaram 0 projeto de pesquisa e, posteriormente, aplicaram um questionário para caracterizar as participantes do estudo, mapear as características, as peculiaridades, as necessidades e as tendências que orientam 0 fazer pedagógico em cada uma das escolas envolvidas. No Encontro II os dados coletados através do questionário foram socializados e analisados em conjunto com as professoras. Também foram discutidos os Referenciais Curriculares Nacionais da Educação Infantil.

b) $2^{a}$ Etapa: Planejamento das ações. A proposição de espaços formativos ganha centralidade nesta segunda etapa. Nesta etapa, foram socializados e discutidos com o grupo de professoras os dados coletados através do questionário. Com base nas reflexões 
oriundas deste momento, foi planejada coletivamente a primeira etapa das ações formativas, tendo por base as demandas das professoras mencionadas no questionário. É importante trazer à tona a posição de Nóvoa (1999, p. 26) quando enfatiza que: "A formação de professores é, provavelmente, a área mais sensível das mudanças em curso no setor educativo: aqui não se formam apenas profissionais; aqui se produz uma profissão".

Foram planejados três minicursos, com duração de 12 horas cada, os quais contemplaram aspectos relativos ao planejamento da ação educativa, a alfabetização e letramento na Educação Infantil e a inserção das tecnologias no contexto educacional. Os minicursos se constituíram em espaços privilegiados para a reflexão crítica das práticas pedagógicas no contexto da Educação Infantil, assim como para o desenvolvimento de estratégias para a formulação de projetos e ações a serem implementados no cotidiano educacional. Assim, os professores não são considerados como meros consumidores de formação, mas como solicitadores de formação e capazes de se apropriarem e conduzirem as suas práticas profissionais e agendas de desenvolvimento (Ribeiro Gonçalves, 2010a). Não basta formar professores. É necessário dar-Ihes oportunidades de gostarem de ser professores.

\section{Campo empírico e participantes do estudo}

O campo empírico do estudo são 31 escolas de Educação Infantil, as quais atendem crianças de 0 a 5 anos. Grande parte destas escolas está situada em bairros da periferia da cidade e atendem crianças provenientes de famílias com baixo nível sócio-econômico. Participam do Programa de Formação Continuada 26 professoras que atuam na pré-escola, situadas na faixa etária entre 24 e 65 anos, sendo que 69\% (18) das professoras se encontram entre 24 e 37 anos. Em relação à maior titulação obtida, 27\% (7) possuem ensino médio, 46\% (12) graduação e 27\% (7) especialização, lato sensu. Quanto ao número de horas que atuam na Escola de Educação Infantil, constata-se que 92\% (24) possuem 30 horas. No que se refere ao tempo de docência na Educação Infantil, 69\% (18) possuem entre 1 a 10 anos de experiência. 


\section{Instrumentos para coleta de dados}

Para a coleta de dados foi utilizado um questionário contendo questões abertas e fechadas, as quais foram categorizadas nas seguintes dimensões: a) biografia profissional; b) representações sobre o contexto escolar; e c) concepções e práticas pedagógicas cotidianas. Importante destacar que, ao ser utilizado o questionário, os pesquisadores tiveram presente, a partir do que colocam Laville e Dionne (1999), Marconi e Lakatos (2006) e Gil (2007), as limitações e possibilidades da utilização deste tipo de instrumento. Quanto as limitações, no que se refere a pesquisa em foco, destaca-se a necessidade de aprofundar algumas dimensões presentes em algumas respostas, a fim de ser possível explorar com mais profundidade o conteúdo manifesto. A superação de tal limitação se dará nas etapas posteriores, com a utilização de outros instrumentos de coleta de dados, tais como a entrevista e a observação das práticas cotidianas.

Para a análise dos dados coletados foi utilizada a técnica de análise de conteúdo proposta por Bardin. Tal análise integra um conjunto de técnicas que possibilitam, através de procedimentos sistemáticos de descrição do conteúdo, a realização de inferências acerca da produção e/ou recepção de determinada mensagem (Bardin, 1988).

\section{Resultados e discussão}

A Educação Infantil é uma fase escolar fundamental para as crianças, principalmente no que se refere à potencialização dos processos de desenvolvimento e aprendizagem e, por isso, tem merecido atenção especial por parte dos governantes, em seus diferentes níveis, das escolas, dos professores e de pesquisadores, dentre outros. Fica claro que a Educação Infantil tem especificações distintas dos outros níveis de ensino, sendo necessário que os seus movimentos contemplem essas particularidades. No entender de Barbosa (2006, p. 25):

(...) as pedagogias da Educação Infantil têm como centro de sua teorização a educação das crianças pequenas, situando-a tanto em sua construção como um sujeito de relações, inserido em uma cultura, em uma sociedade, em uma economia e com formas específicas de pensar e expressar-se, quanto, também, como proposições instrumentais em relação aos aspectos internos, ao funcionamento institucional e aos projetos educacionais, isto é, seus aspectos didáticos como, por exemplo, os programas, as estratégias, os objetivos, a 
avaliação, a definição dos usos do tempo e espaço, sua organização, suas práticas, seus discursos, enfim, sua rotina.

Com base na colocação de Barbosa sobre as pedagogias da Educação Infantil, e tendo presente que tais pedagogias são materializadas pelos docentes que atuam nesta etapa educativa, é necessário questionar que saberes (experienciais, curriculares, disciplinares e de formação profissional) são mobilizados em suas práticas educativas. Conforme Tardif (2010, p. 11):

(...) o saber é sempre o saber de alguém que trabalha alguma coisa no intuito de realizar um objetivo qualquer. Além disso, o saber não é uma coisa que flutua no espaço: o saber dos professores é o saber deles e está relacionado com a pessoa e a identidade deles, com a sua experiência de vida e com a sua história profissional, com as suas relações com os alunos em sala de aula e com os outros atores escolares na escola, etc. Por isso é necessário estudá-lo relacionando-o com esses elementos constitutivos do trabalho docente.

Nesse sentido, Tardif faz menção àquilo que ele denomina como sendo a "epistemologia da prática profissional", ou seja, o "estudo do conjunto dos saberes utilizados realmente pelos profissionais em seu espaço de trabalho cotidiano para desempenhar todas as suas tarefas" (Tardif, 2002, p. 225, grifo do autor). Considerando as professoras como produtoras de saberes e que tais saberes são norteadores de suas práticas, o conhecimento de "quem é esse profissional, sua trajetória escolar, sua formação básica, como ele se desenvolve ao longo de sua trajetória profissional é (...) de fundamental importância quando se pensa em oferecer um ensino de qualidade" (Mizukami, 1996, p. 60). Nessa perspectiva, na sequência, são apresentados saberes que traduzem as concepções das professoras da Educação Infantil, participantes da pesquisa.

As respostas das professoras sobre os motivos que influenciaram na opção pela docência podem ser agrupadas nas seguintes categorias: a) 46\% (12) o gosto e prazer por ensinar; 19\% (5) a influência de figuras parentais ou de pessoas de referência (professores, colegas); 19\% (5) o amor e o gostar de crianças; $12 \%$ (3) a vocação; e 4\% (1) a necessidade de inserção no mercado de trabalho. A idéia do magistério como vocação remete a construção histórica da própria profissão. Ou seja, conforme salienta Nóvoa (1999, p. 15): "Inicialmente, a função docente desenvolveu-se de forma subsidiária e não especializada, constituindo uma ocupação secundária de 
religiosos ou leigos das mais diversas origens". Assim: "A gênese da profissão de professor tem lugar no seio de algumas congregações religiosas, que se transformaram em verdadeiras congregações docentes" (ibidem). Apesar de todas as discussões acerca da constituição e da profissionalização docente, ainda se constata que a visão do professor como alguém vocacionado se encontra arraigada entre aqueles que optam por esta profissão, conforme ilustra a fala da professora 23: "É vocação (...) desde criança sempre tive vontade de lecionar e ajudar as pessoas em suas dificuldades (...) cresci auxiliando as professoras até me formar no magistério e ter a minha própria turma".

Os fatores mais citados pelas professoras que interferem no exercício da ação profissional são: formação inicial e continuada (19); condições e ambiente de trabalho adequado às necessidades e exigências da ação docente (19); remuneração (8); recursos materiais (6); e parceria com a família (5). Do conjunto de professoras, $46 \%$ (12) mencionam que não encontram dificuldades para exercer sua função como professora na Educação Infantil. As professoras que dizem encontrar dificuldades justificam suas respostas explicando que tais dificuldades são oriundas: da ausência de espaços e tempos, dentro do horário de trabalho, para o estudo e o planejamento da ação educativa; da carência de subsídios didáticopedagógicos (materiais, livros, recursos); da necessidade de se ter um profissional de apoio atuando junto com a professora titular da turma; e do número elevado de alunos por turma. Os fragmentos a seguir ilustram tais posições:

Preciso ter mais formação. O que fazer com crianças que necessitam de uma ajuda psicopedagógica?. (...) acho que as escolas de educação infantil oferecem pouco amparo ao profissional da sala de aula (Professora 8).

Sinto falta de um profissional que auxilie na organização da sala, pois o próprio professor além de dar conta da parte pedagógica, como plano, anotações, aplicações das atividades, ainda precisa auxiliar as crianças em tudo, desde do banheiro, limpeza da sala, socorrer em caso de acidente e mediando conflitos (Professora 12).

Às vezes encontramos nossos contratempos por não possuir espaço para planejar nem estudar (no horário de trabalho), falta incentivos como a qualidade do tempo oferecido, faltando muitas vezes os materiais que a educadora acaba comprando para não deixar de fazer (Professora 26). 
É possível observar a ênfase dada pelas professoras à formação docente como um dos fatores que interfere no exercício da docência. Sem dúvida, não é mais possível conceber que o professor, na contemporaneidade, possa ter o mesmo perfil de épocas passadas, em que o domínio de um conjunto de conhecimentos e de determinadas técnicas era o suficiente para exercer o ofício de professor. Carrolo (1997, p. 30), ao se referir à profissionalização docente, enfatiza que "esta profissão é altamente complexa e especializada, não só quanto ao seu saber profissional específico e à forma como é avaliada a sua legitimação, como quanto ao seu processo de formação/socialização inicial". Redin (2000, p. 50) salienta que: "Por ser Educação Infantil, um espaço e tempo pedagógico, tem ela uma função educativa explícita, organizada, que exige ação de profissionais especificamente preparados". No entender do autor:

O profissional da educação infantil deverá ter um preparo especial, porque para a infância exige o melhor do que dispomos. Mesmo porque, na relação pedagógica, não basta estar presente para ser um bom companheiro. Deverá ter um domínio dos conhecimentos científicos básicos, tanto quanto conhecimentos necessários para 0 trabalho com a criança pequena (conhecimentos de saúde, higiene, psicologia, antropologia e história, linguagem, brinquedos e das múltiplas formas humanas, de desenvolvimento físico e das questões de atendimento em situações de necessidades especiais). Precisa ainda ter sob controle seu próprio desenvolvimento, bem como estar em constante processo de construção de seus próprios conhecimentos. Ter elaborado, maduramente, a questão de seus valores, cultura, classe social, história de vida, etnia, religião e sexo (Redin, 2000, p. 51).

A boa convivência no local de trabalho - 54\% (14) - e as relações colaborativas entre os profissionais que atuam na escola - $46 \%$ (12) - são pontos considerados satisfatórios para o grupo de professoras. Contudo, no entender de $50 \%$ (13) das professoras, a escola poderia envolver mais a comunidade local nas suas ações educativas.

Quanto às características da criança que frequenta a Educação Infantil, as mais indicadas nas respostas das professoras são: curiosidade e vontade de aprender (24); alegria (9); afetividade (8); criatividade (6); e autenticidade (5). Chama a atenção o fato de que o brincar foi citado somente por uma professora. Tal fato remete a discussão tanto sobre o papel do brincar, quanto às transformações que foram ocorrendo em relação às diferentes representações sociais da infância, pois tais noções foram se 
constituindo e se configuram em consonância com o contexto sócio-cultural, político e econômico vigentes em determinada sociedade. Relacionada à concepção de criança e infância, emerge a forma de se pensar o brincar e o papel por ele ocupado no desenvolvimento infantil. Nesta perspectiva, Moyles (2002, p. 11) questiona:

(...) será que brincar é verdadeiramente valorizado por aqueles envolvidos na educação e na criação de crianças pequenas? Com que frequência o brincar e a escolha dos materiais lúdicos são reservados como uma atividade para depois de as crianças terminarem o "trabalho", reduzindo tanto seu impacto quanto seu efeito sobre o desenvolvimento da criança? Quantas crianças chegam à escola maternal incapazes de envolver-se no brincar, em virtude de uma educação passiva que visa o brincar como uma atividade barulhenta, desorganizada e desnecessária? (grifo da autora).

Através do brincar, a criança (re)organiza sua realidade e desenvolve sua criatividade, identidade, autonomia, imitação, memória e imaginação. Também amadurece suas capacidades de socialização, por meio da interação e da experimentação de regras e papéis sociais. Conforme Vygotsky (1991, p. 110): "É no brinquedo que a criança aprende a agir numa esfera cognitiva, ao invés de numa esfera visual externa, dependendo das motivações e tendências internas, e não dos incentivos fornecidos pelos objetos externos". Os objetos, continua o autor, "(...) perdem sua força determinadora. A criança vê um objeto, mas age de maneira diferente em relação àquilo que ela vê. Assim, é alcançada uma condição em que a criança começa a agir independentemente daquilo que ela vê" (ibidem). Ou seja, a ação no brinquedo é distinta da ação na vida real porque: "No brinquedo, a ação está subordinada ao significado; já, na vida real, obviamente a ação domina o significado (Vygotsky, 1991, p. 116). O brincar viabiliza a criação de situações imaginárias e, através delas, a criança atribui novos significados aos objetos e norteia sua ação não mais a partir do percebido, mas sim do imaginado. Tal ação exige e possibilita à criança o controle voluntário de suas ações e o desenvolvimento do pensamento abstrato. Para que a criança possa brincar, é necessário que sejam assegurados tempos e espaços (Redin, 2000), pois é comum o cerceamento desses espaços e tempos em detrimento de atividades consideradas "sérias". Assim, ao negar o direito ao brincar, também se negam as possibilidades de, através desse brincar, a criança vivenciar plenamente sua infância (Sarmento \& Rapoport, 2009b). 
O brincar é uma das linguagens utilizadas pela criança para manifestar e comunicar suas idéias e sentimentos. Além do brincar, outras linguagens foram se desenvolvendo, antes mesmo da criança tornar-se aluno e ingressar no ensino formal, como por exemplo a linguagem plástico-visual (desenho, pintura, modelagem), linguagem sonoro-visual (música), linguagem gestualcorporal (dança, dramatização) (Junqueira Filho, 2005). Nesse sentido, entende-se que é função da escola propiciar um ambiente alfabetizador para que a criança possa desenvolver as diversas linguagens. Dessa forma, os modos de compreensão dos pais e educadoras que atuam no contexto da Educação Infantil sobre o brincar e demais linguagens infantis trazem implicações para as práticas educativas direcionadas à infância que, em decorrência, podem contribuir ou não para o desenvolvimento das capacidades e potencialidades da criança.

$\mathrm{Na}$ ótica de $92 \%$ (24) das professoras, as crianças são protagonistas no ambiente escolar, sendo que $100 \%$ delas destacam que as situações de atividades propiciadas valorizam a autonomia e os conhecimentos prévios infantis, 92\% (24) enfatizam que as crianças são consultadas sobre a qualidade das aulas e $96 \%$ (25) salientam que os temas a serem trabalhados são antecipados aos alunos. Müller e Redin (2007, p. 17) evidenciam que: "Nas atividades e na forma de planejá-las e acompanhá-las, estão presentes suas concepções de infância, de educação, de ensino, de aprendizagem, ou seja, de cultura". Por ser a infância uma construção social, ela sofre alterações com o passar do tempo. É na modernidade que surge a idéia de infância e de criança veiculada na atualidade. Moraes $(2004$, p. 2) destaca a evolução da sociedade e, juntamente com ela, a evolução dos conceitos de infância e criança:

Quando falamos de infância, muitas vezes nos deparamos com concepções que desconsideram que os significados que damos a ela dependem do contexto no qual surgem e se desenvolvem e também das relações sociais nos seus aspectos econômico, histórico, cultural, político, entre outros aspectos, que colaboram para a constituição de tais significados e concepções que, por sua vez, nos remetem a uma imagem de criança como essência, universal, descontextualizada ou então nos mostram diferentes infâncias coexistindo em um mesmo tempo e lugar. Necessário, talvez, seria lembrar que as imagens de criança encarnam uma idéia de infância sempre recortada pelos referenciais que buscamos como base para concebê-las. 
A organização dos tempos e espaços da Educação Infantil precisa ser cuidadosamente planejada e preparada, para que as crianças possam se desenvolver integralmente. Corroborando o que afirma Hoffmann (2000, p. 33), é importante destacar que:

O espaço pedagógico que respeita e valoriza a criança no seu próprio tempo é, antes de mais nada, um ambiente espontâneo, seguro e desafiador. Espontâneo no sentido de favorecer a exploração livre dos objetos, da vivência de situações adequadas ao tempo da criança, onde possa escolher brinquedos ou parceiros, num ritmo próprio, mesmo que diferente entre elas, sem pressões ou expectativas dos adultos a serem cumpridas. Um ambiente acolhedor, porque será compreendida e acompanhada pelo adulto, pronto a ampará-la, a conversar com ela, a dar-Ihe todo o afeto e orientação necessária. E, ao mesmo tempo, desafiador, porque planejado e organizado pelo professor com base nas conquistas da própria criança e sempre na direção de novas conquistas.

Os referenciais teóricos que alicerçam as práticas educativas, segundo as professoras que responderam a esta questão, estão fundamentados nos pressupostos de autores tais como Freire (6 indicações), Piaget (5 indicações) e Vygotsky (4 indicações). Os autores citados pelas professoras são alguns dos utilizados como referencial no projeto pedagógico da rede municipal. Autores como Ferreiro, Zabalza, Kamii, Ventura, Decroly e Freinet foram referidos uma vez cada. Com menor frequência, foram citados documentos norteadores tais como o Referencial Curricular Nacional da Educação Infantil e a Proposta Pedagógica da Escola. Somente uma professora citou as Diretrizes Municipais para a Educação Infantil. Estabelecendo relações entre as respostas das professoras sobre as características infantis e os referenciais teóricos mais citados por elas, que embasam suas práticas educativas, parece haver uma lacuna, pois questões fundamentais presentes nos pressupostos de Piaget e Vygotsty no que toca ao desenvolvimento e aprendizagem na infância foram tangenciadas. Os modos de efetivação dos pressupostos dos autores citados pelas professoras, que balizam seus fazeres pedagógicos, merece ser investigado. Dessa forma, será possível discutir as inter-relações entre a teoria e a prática no contexto da docência na Educação Infantil.

Por fim, as professoras consideram que, para que as suas práticas educativas possam incidir sobre os processos de desenvolvimento e aprendizagem infantil, é fundamental: a disponibilização de subsídios materiais; a formação continuada dos professores; a constituição de uma rede 
de apoio ao professor, alunos e família composta por uma equipe multidisciplinar; espaços e tempos para o estudo, a pesquisa e o planejamento, no horário de trabalho.

\section{Considerações finais}

Formação e qualidade em educação são duas dimensões interrelacionadas. Ou seja, para ser viável o alcance de indicadores de desempenho mais elevados, é necessário investir na formação daqueles que estão à frente dos processos de ensino e aprendizagem - os professores -, formação esta compreendida sob a perspectiva da formação integral, transversalisada nas dimensões pessoal e profissional (Nóvoa, 1999). Corroborando a ênfase de Loiola (2005, p. 2), entende- se que:

(...) a formação continuada das professoras deve se inserir em uma nova perspectiva de desenvolvimento profissional. Acreditamos que é também dentro da própria escola que as professoras podem encontrar alternativas para aperfeiçoar e melhorar suas práticas pedagógicas. Dito de outra maneira, fazse necessário desenvolver estratégias de formação a partir das exigências de suas práticas concretas e das interações com seus pares, procurando, ao mesmo tempo, o apoio de profissionais que trabalham com a problemática de formação de professoras. (...) Em síntese, consideramos que a busca e a concepção de uma proposta de formação continuada é uma necessidade atual que exige uma resposta urgente.

O Programa de Formação Continuada "Escola em Movimento: Saberes e Fazeres em Cena" se constitui numa proposta inovadora em termos de formação continuada porque: a) compreendido sob a ótica de um movimento dialético, está sendo gestado coletivamente entre o governo municipal da cidade de Canoas e suas instâncias representativas, com o aporte teórico-científico e metodológico do Centro Universitário La Salle, consolidando o que estabelece como meta o Plano Nacional de Educação e as Diretrizes Municipais relativas a qualidade da educação; b) configura-se numa política pública municipal de formação articulada com o Plano de Carreira dos professores, sendo totalmente financiado pelo governo municipal; e c) está pautado no princípio do protagonismo reflexivo individual e coletivo dos atores que atuam no contexto educativo buscando contemplar as reais demandas formativas do grupo de professores e gestores envolvidos, superando a posição de meros consumidores de formação. 
Vale ressaltar que este Programa está em fase desenvolvimento e que as considerações até então tecidas acerca de sua importância estão fundamentadas em evidências de caráter preliminar. Neste texto, por exemplo, foi realizado um recorte focalizando-se o grupo de professoras que atuam na Educação Infantil. Contudo, acredita-se que, em médio prazo, será viável o cruzamento de dados coletados com os diferentes grupos formativos, estabelecendo-se, inclusive, parâmetros comparativos no que tange à eficácia do Programa em termos de melhoria nos processos e práticas educativos e aos modos de repercussão nos índices obtidos nos sistemas de avaliação externa.

Enquanto um espaço de reflexão-investigação-ação e revisão das práticas educativas e dos saberes docentes construídos no decorrer das trajetórias docentes, almeja-se que esse Programa possa contribuir para (re)visitar as pedagogias direcionadas à infância, problematizar as concepções de criança e infância que permeiam os discursos e práticas educacionais, as configurações dos tempos e espaços educativos e a formação do professor que exerce a docência na Educação Infantil e anos iniciais do Ensino Fundamental.

Estas considerações finais não podem deixar de trazer à tona algumas limitações que, embora não desqualifiquem os resultados devem, mesmo assim, ser enunciadas. Essas limitações são de natureza instrumental e prendem-se com a utilização de questionários como instrumento de coleta de informação. Os respondentes, por vezes, podem não responder ao que thes é questionado, mas sim ao impacto cognitivo que o conteúdo da pergunta lhes transmite. Este problema pode acarretar uma situação de hiper-subjetividade. Porém, esta dose de subjetividade foi estrategicamente diluída nos encontros de reflexão, discussão e partilha, dando lugar a uma subjetividade disciplinada e objetivada. Quando são utilizados questionários, o contato com o respondente pode ser perdido, eliminando assim a possibilidade de recuperar as razões e significados que estão sob as respostas dadas. Também esta recuperação foi possível através dos encontros constantes do Programa.

Por último, destaca-se que o impacto deste Programa decorre da própria natureza da pesquisa-ação colaborativa. Quer dizer: um membro acaba por trazer outro. Este texto traz-nos testemunhos dos primeiros sujeitos 
envolvidos. É, portanto, um tipo de impacto não imediato, mas de todas as maneiras expectável com o decorrer do tempo. É a ordem natural da replicação e desmultiplicação de membros interessados em pertencer a comunidades que partilham cumplicidades científicas, epistemológicas, pedagógicas, didáticas, culturais e sociais e que, ao mesmo tempo, fazem destas cumplicidades a força para se tornarem mais ativos na mudança das práticas educativas. É a crença neste pressuposto que moveu e continuará a mover este projeto.

\section{Notas}

1 O Programa é oriundo de uma parceria estabelecida entre o poder público municipal (o qual o financia integralmente) e o Centro Universitário La Salle (Canoas/Brasil).

2 Dentre este conjunto de pesquisas, merece destaque a que faz parte do Observatório da Educação, financiada pelo INEP/CAPES, cujo foco é a Alfabetização nos Anos Iniciais do Ensino Fundamental e a formação de professores na Rede Municipal de Ensino de Canoas, e a pesquisa derivada desta, que versa sobre as Práticas Educativas na Educação Infantil nas Escolas Municipais da Rede Municipal de Canoas e Formação de Professores, cujos resultados preliminares estão sendo discutidos neste texto.

3 O quarto ciclo se consolidará com a concessão de bolsas para o Doutorado em Educação.

\section{Referências}

Alarcão, I. (1996). Ser professor reflexivo. In I. Alarcão (Org.), Formação reflexiva de professores: Estratégias de supervisão (pp. 171-189). Porto: Porto Editora.

Alarcão, I. (2001). A escola reflexiva. In I. Alarcão (Org.), Escola reflexiva e nova racionalidade (pp. 15-30). Porto Alegre: Artmed.

Barbosa, M. C. S. (2006). Por amor e por força - Rotinas na Educação Infantil. Porto Alegre: Artmed.

Bardin, L. (1988). Análise de conteúdo. Lisboa: Edições 70.

Bonamino, A. M. C. (2002). Tempos de avaliação educacional: O SAEB, seus agentes, referências e tendências. Rio de Janeiro: Quarteto Editora.

Brasil (1996). Lei $n^{\circ}$ 9.394, de 20 de dezembro de 1996. Estabelece as diretrizes e bases da educação nacional. Brasília? 1996. Disponível em http://www.planalto.gov.br/ccivil_03/Leis/L9394.htm. Acesso em 15/8/2010.

Brasil (2001). Plano de desenvolvimento da educação. Brasília: Ministério da Educação. Disponível em http://portal.mec.gov.br/arquivos/livro/index.htm. 
Brydon-Miller, M., \& Maguire, P. (2009). Participatory action research: Contributions to the development of practitioner inquiry in education. Educational Action Research, 17(1), 79-93.

Carbonell, J. (2002). A aventura de inovar: A mudança na escola. Porto Alegre: Artmed.

Carrolo, C. (1997). Formação e identidade profissional dos professores. In M. T. Estrela (Org.), Viver e construir a profissão professor (pp. 21-50). Porto: Porto Editora.

Correia, J. A. (1991). Inovação pedagógica e formação de professores. Rio Tinto: Edições ASA.

Fortuna, T. (2003). Sala de aula é lugar de brincar? In M. L. M. Xavier \& M. I. H. Dalla Zen (Orgs.), Planejamento em destaque: Análises menos convencionais ( $3^{a}$ ed.). Porto Alegre: Mediação.

Franco, M. A. S. (2005). Pedagogia da pesquisa ação. Educação e Pesquisa, 31(3), 483-502.

Fullan, M., \& Hargreaves, A. (2000). A escola como organização aprendente: Buscando uma educação de qualidade ( $2^{\mathrm{a}} \mathrm{ed}$.). Porto Alegre: Artmed.

Gil, A. C. (2007). Método e técnicas de pesquisa social. São Paulo: Atlas.

Hedges, H. (2012). Teachers' funds of knowledge: A challenge to evidence-based practice. Teachers and Teaching: Theory and Practice, 18(1), 7-24.

Hoffmann, J. (2000). Avaliação na pré-escola: Um olhar sensível e reflexivo sobre a criança. Porto Alegre: Mediação.

Junqueira Filho, G. A. (2005). Linguagens geradoras: Seleção e articulação de conteúdos em Educação Infantil. Porto Alegre: Mediação.

Kemmis, S., \& McTaggart, R. (1992). Cómo planificar la investigación-acción. Barcelona: Laertes Ediciones.

Laville, C., \& Dionne, J. (1999). A construção do saber: Manual de metodologia de pesquisa em Ciências Humanas. Porto Alegre: Artes Médicas.

Lewin, K. (2006). La investigación-acción y los problemas de las minorías. In M. C. Salazar (Org.), La investigación-acción participativa. Inicios y desarrollos (pp. 15-25). Madrid: Editorial Popular; Caracas: Editorial Laboratorio Educativo.

Loiola, L. J. S. L. (2005). Contribuições da pesquisa colaborativa e do saber prático contextualizados para uma proposta de formação continuada de professores de Educação Infantil. In Reunião da ANPEd, 28, 1-16.

Marconi, M. A., \& Lakatos, E. M. (2006). Técnicas de pesquisa: Planejamento e execução de pesquisas, amostragens e técnicas de pesquisa, elaboração, análise e interpretação dos dados. São Paulo: Atlas.

Mizukami, M. G. N. (1996). Docência, trajetórias pessoais e desenvolvimento profissional. In A. M. M. R. Reali \& M. G. N. Mizukami, Formação de professores: Tendências atuais (pp. 59-92). São Carlos: EdUFSCar.

Monceau, G. (2005). Transformar as práticas para conhecê-las: Pesquisa-ação e profissionalização docente. Educação e Pesquisa, 31(3), 467-482.

Moraes, A. A. (2004). Educação Infantil: Uma análise das concepções de crianças e de sua educação nas produções acadêmicas recentes (1997-2002). In Reunião da ANPEd, 27, 1-5. 
Moyles, J. R. (2002). Só brincar? O papel do brincar na Educação Infantil. Porto Alegre: Artmed.

Müller, F., \& Redin, M. M. (2007). Sobre as crianças, a infância e as práticas escolares. In E. Redin, F. Müller \& M. M. Redin (Org.), Infâncias: Cidades e escolas amigas das crianças (pp. 11-22). Porto Alegre: Mediação.

Nóvoa, A. (1999). O passado e o presente dos professores. In A. Nóvoa (Org.), Profissão professor (pp. 13-21). Porto: Porto Editora.

Pimenta, S. G. (2005). Pesquisa-ação crítico-colaborativa: Construindo seu significado a partir de experiências com a formação docente. Educação e Pesquisa, 31(3), 521-539.

Rapoport, A., Sarmento, D. F., Nornberg, M., \& Pacheco, S. M. (2008). Adaptação de crianças ao primeiro ano do Ensino Fundamental. Educação, 31(3), 268-273.

Redin, E. (1998). O espaço e o tempo da criança: Se der tempo, a gente brinca! Porto Alegre: Mediação.

Ribeiro Gonçalves, F. (1993). A observação da relação educativa no processo ensinopartilha-aprendizagem. Algarve: Universidade do Algarve - Centro Universitário de Investigação Educativa.

Ribeiro Gonçalves, F. (2006). A auto-observação e análise da relação educativa: Justificação e prática. Porto: Porto Editora.

Ribeiro Gonçalves, F. (2010a). Da observação de aulas à avaliação do desempenho docente: Cinco princípios, um corolário e uma proposta. O primado da legitimidade explicativa ou as implicações da infra-ecologia. In M. P. Alves \& E. A. Machado (Orgs.), O pólo de excelência: Caminhos para a avaliação do desempenho docente (pp. 54-88). Porto: Areal Editores.

Ribeiro Gonçalves, F. (2010b). Formación y desarrollo de competencias profesionales: Otro reto colocado a la calidad de la enseñanza superior. Una propuesta para Iberoamérica. In C. D. Garrido, A. M. Medina \& M. L. C. González (Coords.), Investigación e innovación de la docencia universitaria en el espacio europeo de educación superior (pp. 65-75). Madrid. Ramón Areces.

Sarmento, D. F., \& Rapoport, A. (2009a). Desenvolvimento e aprendizagem infantil: Implicações no contexto do primeiro ano a partir da perspectiva vygotskiana. In A. Rapoport, D. F. Sarmento, M. Nornberg \& S. M. Pacheco (Org.), A criança de 6 anos no Ensino Fundamental. Porto Alegre: Mediação.

Sarmento, D. F., \& Rapoport, A. (2009b). O direito ao brincar e as suas interfaces com o desenvolvimento infantil. In P. Fossatti, E. Pauly \& C. Jamez Díaz, Crianças e adolescentes: Sujeitos de direitos humanos (pp. 89-100). Canoas: Salles Editora.

Sarmento, D. F., Pauly, E. L., Nogueira, S. V., \& Fossatti, P. (2009). Políticas públicas sociais para a infância e suas implicações para a educação familiar e escolar. Intermeio, 15(29), 180-196.

Schön, D. A. (1992). Formar professores como profissionais reflexivos. In A. Nóvoa (Coord.), Os professores e sua formação (pp. 77-91). Lisboa: D. Quixote.

Schön, D. A. (2000). Educando o profissional reflexivo - Um novo design para o ensino e a aprendizagem. Artmed: Porto Alegre. 
Tardif, M. (2010). Saberes docentes e formação profissional. Petrópolis: Vozes.

Vieira, L. M. F. (2010). A Educação Infantil e o Plano Nacional de Educação: As propostas da CONAE 2010. Educação \& Sociedade, 31(112), 809-831.

Vygotsky, L. S. (1991). A formação social da mente (4a ed.). São Paulo: Martins Fontes. 
TEACHER TRAINING, PROFESSIONAL KNOWLEDGE AND EDUCATIONAL PRACTICES: THE QUALITY OF EARLY CHILDHOOD EDUCATION

\begin{abstract}
The article focuses the professional knowledge that permeates the educational practices of teachers of Early Childhood Education in Brazil, who participated in the In-service Training Program "Escola em Movimento: Saberes e Fazeres em Cena". It emphasizes that the increase in the quality indicators of education presupposes the existence of public policies directed to the monitoring of such indicators, the managers' and teachers' training and the offer and maintenance of conditions that enable the teaching and learning processes.
\end{abstract}

Keywords

Teacher training; Professional knowledge; Educational practices; Quality indicators of education

\title{
FORMACIÓN DE PROFESORES, SABERES DOCENTES Y PRÁCTICAS EDUCATIVAS: LA CALIDAD DE LA EDUCACIÓN INFANTIL EN CUANTO CENTRALIDAD
}

Resumen

El artículo aborda los saberes docentes que permean las prácticas educativas de profesores en escuelas de Educación Infantil de Brasil, participantes del Programa de Formación Continuada "Escola em Movimento: Saberes e Fazeres em Cena". Resalta que el aumento de los indicadores de calidad de la educación implica la existencia e implementación de políticas públicas para 
el monitoreo de dichos indicadores, la formación de gestores y docentes y la oferta y manutención de condiciones que viabilicen los procesos de enseñanza y aprendizaje.

Palabras-clave

Formación de profesores; Saberes docentes; Prácticas educativas; Indicadores de calidad de la educación

Recebido em Maio/2011

Aceite para publicação em Abril/2012

Toda a correspondência relativa a este artigo deve ser enviada para: Dirléia Fanfa Sarmento, Av. Victor Barreto, 2288, Centro, Canoas, Rio Grande do Sul, CEP 92110-000, Brasil. Telef.: (55) (51) 980268 65; E-mail: fanfa@unilasalle.edu.br 